\title{
Dois olhares e uma guerra
}

Two views and a war

Deux regards et une guerre

\section{Laura Cavalcante Padilha}

\section{(2) OpenEdition}

\section{Journals}

Edição electrónica

URL: http://journals.openedition.org/rccs/1087

DOI: $10.4000 /$ rccs. 1087

ISSN: 2182-7435

\section{Editora}

Centro de Estudos Sociais da Universidade de Coimbra

\section{Edição impressa}

Data de publição: 1 Junho 2004

Paginação: 117-128

ISSN: 0254-1106

Refêrencia eletrónica

Laura Cavalcante Padilha, "Dois olhares e uma guerra », Revista Crítica de Ciências Sociais [Online], 68 | 2004, colocado online no dia 01 outubro 2012, criado a 01 maio 2019. URL : http:// journals.openedition.org/rccs/1087; DOI : 10.4000/rccs.1087 


\section{LAURA CAVALCANTE PADILHA}

\section{Dois olhares e uma guerra}

A partir da leitura das obras poéticas Sangue negro (2001) e É nosso o solo sagrado da terra (1978), respectivamente de Noémia de Sousa e Alda Espírito Santo, o texto procura surpreender dois olhares africanos sobre a guerra, em perspectiva ao mesmo tempo étnica e de género. Para além disso, discute-se o duplo gesto de nomeação do conflito; a mudança, no universo discursivo, do sistema de referências imposto pelo colonialismo e, consequentemente, a encenação da interioridade de novos sujeitos históricos femininos.

É preciso arrancar da boca do silêncio a comida da palavra e deixar que se semeie por aí à solta, porque o ódio, esse pega de estaca.

Ana Paula Tavares

A frase por onde começo, retirada de uma crônica da autora ("Manifesto", Tavares, 1998: 32-33), parece dar conta, embora seu objetivo não seja a questão da Guerra Colonial, do que se passa no imaginário africano nos chamados anos da luta e/ou naqueles em que se dá a sua preparação. No afã de reverter o estado de ódio que a estaca do colonialismo implantou e fez crescer, os produtores literários procuram "arrancar da boca do silêncio a comida da palavra", semeando-a no solo do texto. É o que aconteceu com o gesto de semeadura de duas mulheres que se fazem, recorrendo uma vez mais a outra crônica da mesma Ana Paula, "o rosto visível da história que, quanto ao mais, se encarrega de esquecer a metade silenciada da humanidade" (1988: 103). São elas a moçambicana Noémia de Sousa (1926-2002) e a santomense Alda Espírito Santo (1926).

A leitura de Sangue negro, escrito entre 1948 e 1951, por Noémia, mas só publicado em 2001/2002, e de É nosso o solo sagrado da terra, 1978, de Alda, mostra-as como narrativas de guerra em seu mais amplo sentido, não obstante o registro lírico que as enforma. A primeira anuncia a guerra como desejo e urgência histórica, embora o significante em si apareça pouco nas malhas textuais. Ele de certo modo se camufla em outros pelos quais se evidencia o estado de beligerância, marca do eu-lírico: ameaça, raiva, grito, revolta, luta, todos adensados no corpo dos poemas. 
Já com relação a Alda, a guerra se apresenta com toda a sua crueza, desdobrando-se em várias direções semânticas: massacre, guerrilha, martírio, sangue, devastação. O conflito aí encenado e os mártires da causa, para além de vários de seus heróis, tomam lugar na cena poética, em uma espécie de reconvocação histórica para que a sua memória sobreviva. É o que se dá com o poema de Alda para Deolinda Rodrigues, militante angolana desaparecida no confronto.

Irmã, a terra mártir

Embebeu teu sangue

Alastrando sobre o continente inteiro

Como uma sementeira

florescente de glória.

(Santo, 1978: 114)

Retorna aqui a metáfora da semente tão produtiva nos anos da luta, bem como a do sangue como agente fertilizador da terra e do futuro. O movimento é sempre de expansão e os corpos martirizados se encenam com força e de modo expressionista, como se dá com o quadro seguinte, desenhado pelas palavras de Noémia pelas quais tenta traçar o mapa de um corpo cultural silenciado e agônico, na clave do feminino, mostrando-lhe as veias abertas, bem como suas

órbitas vazias no desespero de possuir a vida,

boca rasgada em feridas de angústia,

mãos enormes, espalmadas,

erguendo-se em jeito de quem implora e ameaça,

corpo tatuado de feridas visíveis e invisíveis

pelos chicotes da escravatura...

(Sousa, 2001: 49)

Há, desse modo, um deslocamento do suporte ético sobre o qual a colonialidade, com suas rasuras e apagamentos, se erguera. Lucía Guerra analisa de modo pertinente:

En todo sistema de colonización, el Sujeto colonizador marginaliza de la Historia al Otro colonizado con el objetivo de mantener su posición de poder en la inmovilidad absoluta. (Guerra, 1995: 26)

Tal sujeito marginalizado, ao tomar consciência de si e de sua história, começa a querer desimobilizar-se, ação pela qual emergem outros valores a 
demandarem um também outro conjunto de normas para sustentar o processo de decodificação. Não se trata de substituir os centros, trocando um pelo outro, como adverte Edward Said, mas de ampliar e refinar um procedimento em cujo centro, isso sim, sempre avultaram os parâmetros éticos e estéticos do europeu colonizador, no presente caso, em sua versão portuguesa. A mobilização objetiva que a voz secularmente silenciada se faça ouvir e que o corpo se deixe conhecer, daí o título do poema de Noémia atrás citado, "Se me quiseres conhecer", a indicar a mudança da direção do olhar, pois o sujeito histórico, sempre se pensando como um coletivo - e agora os versos são de Alda -, empenha-se em afirmar o seu querer: "Nós queremos a nossa hora/A hora dos nossos passos" (Santo, 1978: 99). Ou seja: propõe-se um novo sistema de referências, pelo qual se consiga reverter a destruição dos valores culturais, no sentido trabalhado por Frantz Fanon en Pela revolução africana (Fanon, 1975).

Neste ponto, queria começar, mesmo correndo o risco de insistir no óbvio, pela questão da duplicidade fundante do olhar histórico sobre a guerra de independência das hoje nações africanas de língua oficial portuguesa. Para tanto, retomo o ensaio de Marilena Chauí sobre o olhar, onde, dentre outras coisas, ela afirma: "quem olha, olha de algum lugar", havendo sempre, pois, "variação no olhar", isto é, de perspectiva. Citando a filósofa:

Com ela [a perspectiva], o olho do observador se faz medida do visível e prepara, na filosofia, o advento de um sujeito do conhecimento que se julga capaz de evidência e intuição. (Chauí, 1988: 35-37)

Por outra parte, Sérgio Cardoso, na mesma obra organizada por Adauto Novaes, e retomando Merleau-Ponty, esclarece: "o olhar [...] remete, de imediato, à atividade do sujeito, e atesta a cada passo nesta ação a espessura de sua interioridade" (Cardoso, 1988: 348). Ora, quando se pensa a guerra de que falamos, deve-se necessariamente considerar essas duas noções básicas: perspectiva e interioridade dos sujeitos em enfrentamento, pois, na relação colonizado vs. colonizador, elas são absolutamente conflitantes. Nota-se, ainda, que tal conflito se maximiza ainda mais na era cunhada por Eric Hobsbawm como a dos nacionalismos (Hobsbawm, 1990) e que corresponde ao movimento da luta africana.

A duplicidade do olhar do oprimido e do opressor leva a uma nomeação divergente e igualmente dupla, para além de gerar duas formas narrativas. Para o poder metropolitano, a guerra se fazia necessária como um movimento, estertorado embora, de preservação de territórios apontados pelo imaginário político como seus, porque perenes fontes de lucro, mormente 
após a mudança da forma de organização política da ocupação ultramarina, decorrência das imposições da Conferência de Berlim (1884-1885). Com a perda do Brasil e com tais imposições, o império português se consolida no continente africano. A narrativa surgida nesse momento de ameaça e de perda, que leva à guerra, tem, portanto, assegurado o seu sentido dentro da macro-narrativa histórica do imperialismo.

Por outro lado, para os povos vistos como subalternos pela perspectiva do olhar eurocêntrico, porque "ontologicamente dados", na expressão de Said, a guerra se apresenta de modo diametralmente inverso e em franca rota de colisão. Não se trata de preservação, mas de ruptura e enfrentamento. Sai-se do reino da narrativa, adentrando-se o da "contra-narrativa de libertação" (Said, 2003: 135-136). Em “Giovani”, Alda Espírito Santo elabora tal dissidência narrante, ao dizer:

As últimas balas coloniais

Descarregaram toda uma epopeia sangrenta

No corpo de Giovani estirado na via pública.

As últimas balas à hora do meio-dia

Badaladas decisivas

do Relógio da Revolução

Sepultaram o colonialismo

No cadafalso do Povo.

(Santo, 1978: 179)

O movimento anti-colonialista se alicerça ideologicamente como revolução e não como mais uma das muitas guerras travadas em solo africano. A luta é para que os povos subjugados tornem seus, por direito inalienável e constituído, o que sabem ser seus por direito de pertença. Em carta datada de 1960 à mesma Deolinda Rodrigues, Lúcio Lara, um dos líderes do Movimento Popular de Libertação de Angola, expressa com clareza o sentido de tal ação anti-colonialista:

[...] temos o dever imperioso de lutar até ao limite das nossas forças para que a repressão feroz não deite a perder o que com tanto sacrifício se consolidou - a consciência nacional do nosso Povo. [...] Este movimento engloba nativos de todas as colónias portuguesas de África [...] desde que estejam dispostos a lutar dentro de suas possibilidades pela independência de suas pátrias. (Lara, 1997: 223-224)

Propõe-se, então, uma nova cartografia pela revaloração dinâmica da cultura própria, arrancando-se da boca do silêncio, repetindo Ana Paula, a 
comida das novas palavras de ordem então pronunciadas. A guerra se torna a resposta inevitável desse movimento - pensando com Fanon - cujo alvo é a libertação total do espaço territorial subjugado (Fanon, 1975: 50-51). O que se quer é a mudança do sentido de propriedade, voltando o africano, parodiando Kwame Anthony Appiah (1997), a ser o dono da casa do seu pai. Se tudo se resolve, só o tempo vai dizer, como, aliás, parece estar dizendo...

Saindo do campo parentético, necessário para se esclarecer a duplicidade fundante do olhar sobre a guerra, retorno a Noémia de Sousa e a Alda Espírito Santo, cujos poemas se fazem sintomáticos dessa postura histórica rebelde e revalorativa. Eles significam uma espécie de resposta à síndrome da subjugação pela qual o sujeito histórico africano permaneceu em exílio, mesmo sem nunca ter deixado a própria terra. Se o exílio é o máximo do despaisamento, pela ausência do reconhecível e das referências identificatórias, o estar exilado em seu próprio lugar, sofrendo a confrontação simbólico-cultural a cada passo, se faz o exílio dos exílios, já que os modos de viver legítimos são alvo de uma profunda desconfiança histórica do opressor, para quem sempre significaram uma menos valia cultural. A “fratura incurável" do exílio, usando palavras de Said (2003: 46 ss.), se torna muito mais exposta quando se dá dentro e não fora dos territórios de origem e de experiências. Lembro os versos seguintes de Noémia:

Somos os despojados, somos os despojados!

Aqueles a quem tudo foi roubado,

Pátria e dignidade, Mãe e riquezas e crença e Liberdade!

(Sousa, 2001: 42)

Do mesmo modo que as mulheres, os povos colonizados foram, como analisa ainda Lucía Guerra, privados "de su propia Historia y de las historias que modelizan su propia experiencia" (1995:25-26). O quadro se adensa ainda mais quando o sujeito produtor de texto, como é o caso, vive em uma dupla exclusão, seja por seu gênero, seja por sua pertença étnico-cultural. O resultado é a elaboração de uma literatura dissidente, termo de Lucía, ou duplamente dissidente, acrescento, pela qual

los contratextos se elaboran principalmente invirtiendo o deformando modelos y paradigmas en los cuales también están presentes los rasgos relevantes en la construcción imaginaria de la mujer como Otro. (Guerra, 1995: 28-29)

A "construção imaginária como Outro" também atinge o africano. Assim, na condição de mulheres e africanas, ou seja, como seres humanos dupla- 
mente colonizados, Noémia e Alda declaram-se em guerra e fazem seu comunicado em forma de poesia. É o que, a partir de agora, esta intervenção privilegiará, trazendo à cena, de modo esquemático, as duas falas de mulher e suas interioridades e perspectivas. Caminharemos pelos mapas onde se traçaram os acidente geográficos de um tempo de silêncio e o impulso incoercível dos sujeitos assim cartografados de romperem tal silêncio, com raiva e urgência. Para além das obras literárias editadas, outras falas dessas duas mulheres africanas serão aqui convocadas, como entrevistas, ensaios, etc., em busca de surpreender a perspectiva de seus

\section{Olhares em confluência}

Como sabemos, Noémia só escreve até 1951, ano em que deixa Moçambique, como ela diz, "porque estava muito visada pela Pide" (Chabal, 1994: 118). Assim, sua produção não se liga diretamente aos anos da guerra, ao contrário de Alda que a vive e representa de modo intenso, até o estalar das "últimas balas coloniais". Depois, ela cobre o tempo da libertação e exalta o sentido histórico da conquista da independência. É o que mostram os trechos de seus poemas a seguir:

Cinco séculos estrangeiros no solo pátrio

Regressamos do exílio da exploração

Expulsando com a força do povo

O colosso colonial e seus sequazes.

(Santo, 1978: 181)

$\mathrm{Na}$ grande praça do povo

Clarins em regozijo

Ressoam soltando amarras.

Ó povo do meu país

$\mathrm{O}$ hino da independência

Cala fundo...

Cala fundo...

(ibid.: 161)

O fato dessas duas vivências poéticas temporalizadas distintamente leva a dois estágios diferentes do olhar sobre a guerra. Para Noémia, desejo e esperança. Para Alda, desejo, esperança, realização e vitória. Não obstante isso, há muitos pontos de confluência de seus olhares que perspectivam a mesma experiência histórica, no decorrer dos anos 50, quando compartilham a ebulição do projeto nacionalista africano em Lisboa, freqüentando 
os espaços onde tal projeto se fomentava, como a casa da tia de Alda, Andreza; o Centro de Estudos Africanos; a Casa dos Estudantes do Império; etc. Como diz Alda, em entrevista a Michel Laban: "Criámos encontros com mulheres, através da Maria Vilhena Rodrigues, e Noémia de Sousa, Rute Neto e outras" (Laban, 2002: 77).

A teia, sempre uma simbolização tão feminina, se entretece com mais vigor com os fios de outras mulheres mobilizadas pelo mesmo sonho. A cumplicidade entre Alda e Noémia, partes da teia, acaba por se projetar no modo como passam a conceber o texto, nele imprimindo suas marcas históricas, como se fossem digitais. Tais marcas assim digitalizadas se deixam entrever tanto na própria forma de pensar e realizar o poema como materialidade discursiva, quanto nos temas sobre os quais se debruçam e cujo traço mais significativo talvez esteja na ânsia de contribuir para a criação de uma nova humanidade, no que fazem eco, por exemplo, com Fanon para quem "a descolonização é, em verdade, criação de homens novos" (1979: 26).

Pelos textos de Alda e Noémia, podem-se perceber pontos de convergência no que concerne a suas carpintarias poéticas onde a dissidência se faz a principal meta do movimento de produção artística. Há um estremecimento nos africanos padrões versificatórios femininos de modo geral. A leitura das antologias então produzidas, principalmente pela CEI, e mesmo a análise do boletim Mensagem, por ela publicado, são disso uma evidência que aqui não cabe explorar. Por agora, basta insistir no fato de que seus textos se fazem dissidentes, de certo modo declarando também uma guerra no plano escritural.

A emoção dos sujeitos líricos, a sua rebeldia e insubordinação impedem qualquer pacto de submissão na forma poética. Os poemas ora têm um ritmo longo e frenético, ora se encurtam e como que os versos estalam como se fossem chicotes ou ruído de bala. Não há qualquer rigidez no esquema rímico e na estrofação. Por outro lado, as línguas nacionais africanas reforçam a dissidência, a rebelião e o reforço da alteridade:

Com sonhos de melodia no fundo dos olhos abertos somos os muchopes de penas saudosas nos chapéus de lixo; zampunganas trágicos - xipócués vagos nas noites munhuanenses, e mamparras coroados de esperança, e magaíças, e macambúzios com seu shipalapala ecoando chamamentos...

[...] somos os que não têm lugar na Vida, ah na Vida que se abre luminosa, com cada dia de pétala!

(Sousa, 2001: 41-42) 
Aqui tens o meu poema, irmão.

Meu poema insuficiente e baço, palavras, sangue, emoção, grito que se soltou do fundo das veias e ficou pairando feito estandarte...

(Sousa, 2001: 105)

Não gritaremos mais

Os nossos cânticos dolorosos

Prenhes de eterna resignação...

Outro canto se elevará, Irmãs

Por cima das nossas cabeças

(Santo, 1978: 75)

Coqueiros e palmares da Terra Natal,

Mar azul das ilhas perdidas na conjuntura dos [séculos

[...]

Sedenta de espaço e de vida

Nos cantos amargos do ossobô

$[\ldots]$

Ilhas paradoxais do Sul do Sará

Os desertos humanos clamam

$\mathrm{Na}$ floresta virgem

Dos teus destinos sem planuras...

(ibid:: 37)

Voltando à questão da guerra e do desejo de criação de uma nova humanidade, e ainda dada a brevidade requerida por esta minha fala, deixo outros pontos de confluência significativos, elegendo apenas dois como objeto de meu próprio olhar leitor: a cartografia pronominal dos poemas e o pacto com a configuração de um espaço solidário de fraternidade que acaba por se transformar na principal estratégia bélica para o enfrentamento das forças do inimigo.

Começando pelo processo de pronominalização. Sabemos ser o pronome, com o dicionarista e filólogo Antenor Nascentes, a "palavra que denota o ente ou a ele se refere, considerando-o apenas como pessoa do discurso" (1972, V: 1341-b). Assim ele, o pronome, se faz um elemento lingüístico pelo qual o sujeito se encena no discurso, denotando-se e aos outros imaginários com quem contracena. 
No caso das obras de Alda e Noémia, há um extenso e obsidiante plano pronominal que transita entre o pessoal e o possessivo. Aparecem o eu e o $t u$, levando ao nós, ao mesmo tempo em que o meu, forma de extensão e conseqüência do $e u$, acumplicia-se com o teu, conduzindo ao nosso. O par vós/vosso é menos freqüente. Um levantamento não exaustivo mostrou a prevalência do campo possessivo sobre o pessoal, embora o $e u$ seja a referência maior em Noémia. Em Alda, a grande recorrência é dada pelo par nós/ nosso, este último nosso também adensado no corpo textual da moçambicana.

Por tal via pronominal, é possível detectar-se a mobilização do sujeito poético que revela ser sua subjetividade um fruto do próprio coletivo em que imerge com deliberação. $\mathrm{O}$ eu ganha consistência no processo identificatório com os iguais, daí a resultante que é o nós, pelo qual o tu se engloba. Voltando a Lucía Guerra, pode-se estender para a África e à literatura dissidente então produzida o que a ensaísta afirma sobre a América Latina:

Esta situación de alteridad en un entorno heterogéneo, fracturado y dividido, hace del "nosotros" la señal de aquella diferencia que posee la potencialidad para constituir al otro latinoamericano. (Guerra, 1995: 30)

A alteridade, emergindo em força pela pronominalização em excesso, toma os textos de assalto e como que "ilumina" o encontro fecundante entre o eu que fala, a coisa de que fala e o $t u$, alvo da ação da fala. Chega-se, no jogo inclusivo, ao nós e, principalmente, ao nosso, fim último da declaração de guerra falante e falada. Melhor seria dizer: gritada.

A fraternidade é a via estratégica para que o campo do outro, o dominador, seja minado. O próprio gesto da escritura é forma de reforço dessa fraternidade como mostrou a estrofe do poema de Alda, "Deolinda Rodrigues". Os textos assim concebidos, como os que se encontram no "Livro de João", uma das partes de Sangue negro ou no conjunto "Aos combatentes da liberdade" de É nosso o solo sagrado da terra, podem servir como paradigmas do gesto de fraternidade que anima o impulso de Noémia e o de Alda, fazendo-os confluir para um mesmo lugar simbólico:

Neste anoitecer sangrento de Moçambique

chega-me, segura, a tua voz irmão,

[...]

Misturada com os cantos escravos dos negros

regressando do trabalho,

chega-me de longe a tua voz fraterna,

nítida como a lua cheia no espaço,

[...]

(Sousa, 2001: 112) 
Nessa hora, meu irmão

Iremos cimentar os alicerces

Das nossas vidas

E erguer do braseiro, o nosso país

De África

Num ritmo de tam tans e quissanges

A vida, a paz e a liberdade

$\mathrm{Na}$ grande batucada

Da pátria libertada.

(Santo, 1978: 88)

No conjunto imagístico da fraternidade proposto pelas duas vozes poéticas, destacam-se, para além do constelado irmão, companheiro, amigo, um quadro composicional em feminino - irmã , companheira, amiga, - que serve como elemento intensificador das cores da privação. Não por acaso perceberam vários estudiosos das autoras que elas se debruçam sobre os corpos de suas congêneres, fazendo dos poemas uma forma de resgate dessas figuras de mulher.

A tal propósito, Noémia revela, em entrevista a Patrick Chabal, o porquê do seu debruçar-se:

[...] acho natural [...] são as mães que educam os filhos na nossa sociedade tradicional, que foi sempre machista [...] As mulheres é que transmitem as coisas. Quase todos os contos que eu ouvi eram as mulheres que os contavam, e também as coisas que cantam [...] também as mulheres trabalhavam muito. (Chabal, 1994: 125)

Do mesmo modo, no ensaio "Luares de África", publicado em Mensagem da CEI, Alda analisa a questão da mulher negra, dizendo -

[...] sigo passo a passo a mulher de pele bronzeada - que é a minha história, das avós dos meus avós e da geração futura [...]

[a mulher é] a última que é a última entre os negros que já são últimos na concepção dos demais povos da categoria civilizada [...] A sua voz não se levanta. Morre na distância. Ela nem voz tem. É escrava. - É mulher negra [...] é vítima de todos.

(1949, n. ${ }^{\circ}$, ano I, p. 13-15)

$\mathrm{Na}$ visão das escritoras, portanto, as mulheres são elementos de sustentação e transmissão da cultura (educam, contam, cantam, trabalham) e, de outro, se marginalizam duplamente na história branca, machista e patriarcal. Ao comporem o quadro estético da privação, é uma demanda natural o 
voltar-se para os corpos das iguais, envolvendo-os em, usando uma metáfora cara a Noémia e fragmentos de seus versos, suas "capulanas quentes" "de ternura" e de "compreensão" tecidas por palavras. Não por acaso a mesma Noémia projeta nas "Moças das docas" esse movimento de proteção e esperança, pelo jogo metonímico extensível que vai muito além dos corpos das prostitutas:

Sob o chicote da esperança nossos corpos capulanas quentes embrulharam com carinho marítimos nómadas de outros portos (Sousa, 2001: 93).

Do mesmo modo, Alda canta para as mulheres de sua terra:

Irmãs, do meu torrão pequeno

Que passais pela estrada do meu país de África

É para vós, irmãs, a minha alma toda inteira

(Santo, 1978: 81)

Assim, as mulheres se fazem a face por excelência onde a opressão, a menos valia, a privação, enfim, deixaram suas marcas mais fundas. A guerra acirra tais marcas e, por isso, é preciso cantar para a irmã do mato; as moças das docas; as lavadeiras; as que descascam o caroço ou vendem o peixe nas ruas de bairros miseráveis. Sempre irmãs e negras.

Noémia de Sousa e Alda Espírito Santo, ao oferecerem um lugar em seus textos, para suas iguais em gênero e cor, as envolvem em suas "quentes capulanas" de palavras. O corpo feminino africano é recuperado, nesse espaço de fraternidade consentida, fazendo-se ao mesmo tempo emblema do martírio e da esperança. Por isso, o eu-lírico, vai ao fundo da boca do silêncio em que tal corpo sempre esteve imerso, para, através de sua imagem multiplicada, acumpliciar-se com a nova ordem histórica da liberdade que suas palavras e seus gestos insubordinados procuram construir. Sempre como falas de mulheres em guerra.

\section{Referências Bibliográficas}

ACEI (1994), Antologias de poesia da Casa dos Estudantes do Império 1951-1963. Lisboa:

Associação Casa dos Estudantes do Império (ACEI).

Appiah, Kwame Anthony (1997), Na casa de meu pai: a África na filosofia da cultura. Rio de Janeiro: Contraponto. 
Cardoso, Sérgio (1998), O olhar dos viajantes, in Adauto Novaes (org.), O olhar. São Paulo: Companhia das Letras, 347-360.

Chabal, Patrick (1994), Vozes moçambicanas: Literatura e Nacionalidade. Lisboa: Vega. Chauí, Marilena (1988), Janela da alma, espelho do mundo, in Adauto Novaes (org.), O olhar. São Paulo: Companhia das Letras, 31-63.

Fanon, Frantz (1975), Por la revolución africana. México: Fondo de Cultura Económica [11965].

Fanon, Frantz (1979), Os condenados da terra. Rio de Janeiro: Civilização Brasileira.

Guerra, Lucía (1995), La mujer fragmentada: historias de un signo. Santiago: Cuarto Propio.

Hobsbawm, Eric J. (1990), Nações e nacionalismos desde 1780. Rio de Janeiro: Paz e Terra.

Laban, Michel (1998), Moçambique: encontro com escritores. Porto: Fundação Eng. António de Almeida.

Laban, Michel (2002), S. Tomé e Príncipe: encontro com escritores. Porto: Fundação Eng. António de Almeida.

Lara, Lúcio (1997), Um amplo movimento... itinerário do MPLA através de documentos e anotações. Luanda: Lúcio e Rute Lara.

Mensagem (1996), Mensagem. Boletim da Casa dos Estudantes do Império. Lousã: ALAC.

Nascentes, Antenor (1972), Dicionário ilustrado da língua portuguesa. Rio de Janeiro.

Novaes, Adauto (org.) (1988), O olhar. São Paulo: Companhia das Letras.

Said, Edward (1995), Cultura e imperialismo. São Paulo: Companhia das Letras.

Said, Edward (2003), Reflexões sobre o exílio e outros ensaios. São Paulo: Companhia das Letras.

Santo, Alda Espírito (1978), É nosso o solo sagrado da terra. Lisboa: Ulmeiro.

Sousa, Noémia de (2001), Sangue negro. Maputo: Associação dos Escritores Moçambicanos.

Tavares, Ana Paula (1998), O sangue da buganvília: crónicas. Praia-Mindelo: Embaixada de Portugal/Centro Cultural Português. 